DOI: $10.2478 / \mathrm{v} \cdot 10169-012-0009-9$

\title{
PREDICTION OF ASPHALT CREEP COMPLIANCE USING ARTIFICIAL NEURAL NETWORKS
}

\author{
A. ZOFKA ${ }^{1}$, I. YUT ${ }^{2}$
}

\begin{abstract}
Creep compliance of the hot-mix asphalt (HMA) is a primary input of the current pavement thermal cracking prediction model used in the US. This paper discusses a process of training an Artificial Neural Network (ANN) to correlate the creep compliance values obtained from the Indirect Tension (IDT) with similar values obtained on small HMA beams from the Bending Beam Rheometer (BBR). In addition, ANNs are also trained to predict HMA creep compliance from the creep compliance of asphalt binder and vice versa using the BBR setup. All trained ANNs exhibited a very high correlation of 97 to 99 percent between predicted and measured values. The binder creep compliance functions built on the ANN-predicted discrete values also exhibited a good correlation when compared with the laboratory experiments. However, the simulation of trained ANNs on the independent dataset produced a significant deviation from the measured values which was most likely caused by the differences in material composition, such as aggregate type and gradation, presence of recycled additives, and binder type.
\end{abstract}

Key words: asphalt binder, Hot Mix Asphalt, Artificial Neural Networks, Beam Bending Rheometer, creep compliance, Indirect Tension test.

\section{INTRODUCTION}

An Artificial Neural Network (ANN) is a layered system of neurons with weighted connections. It typically consists of an input layer, an output layer, and one or more hidden layers of interconnected processors (neurons) HAYKIN [1]. Using a sample dataset of input and target values, an ANN can be trained to recognize a relationship between inputs and targets. As early as the late 1980s, civil engineers began using ANN for structural evaluation and traffic analysis (Flood and KarTam [2][3]). Since the 1990s, pavement researchers have successfully used ANNs for analyzing and predicting pavement performance (Dougherty [4], Аттон-Окine and Mensah [5], Chou and Pellinen [6]; TAREFDER et al. [7][8]). In particular, the ANNs were trained to predict rheological properties of bituminous materials in the following applications:

${ }^{1}$ Ph. D., Assistant Professor, Department of Civil and Environmental Engineering, University of Connecticut, 261 Glenbrook Road, Unit 2037, Storrs Mansfield, CT, e-mail: azofka@engr.uconn.edu

${ }^{2}$ M. S., Ph.D. Candidate, Department of Civil and Environmental Engineering, University of Connecticut, 261 Glenbrook Road, Unit 2037, Storrs Mansfield, CT, e-mail: ily08001@engr.uconn.edu 
- Backcalculation of layer moduli for HMA pavements (CEYLAN et al. [9])

- Performance of porous HMA (MolenaAr et al. [10])

- Prediction of pavement fatigue life (HuAng et al. [11])

- Prediction of thermal cracking in the HMA pavements (Zeghal [12])

- Modeling of the HMA creep compliance (Zeghal [13])

- Prediction of dynamic modulus $\left(\mathrm{E}^{*}\right)$ of the HMA from its resilient modulus (LACroix et al. [14], Ceylan et al. [15])

- Evaluation of rubberized HMA containing reclaimed asphalt pavement (XIAO and Amirkhanian [16])

Creep compliance of the hot-mixed asphalt (HMA) mixture is a primary material input for the pavement thermal cracking prediction model in the recently developed Mechanistic-Empirical Pavement Design Guide (M-EPDG) (Haluin et al. [17]). The Indirect Tension (IDT) test is currently the standard procedure for determining the creep compliance of the HMA (Roque and ButtLar [18]). On the other hand, the creep compliance and corresponding creep stiffness of the asphalt binders is typically determined using a Bending Beam Rheometer (BBR) (BAHIA et al. [19]). Previous studies have indicated that using the BBR device for HMA testing is a viable alternative to IDT testing, especially for the practical and surrogate estimation of the HMA creep compliance (ZoFKA et al. [20], ZoFKA and Yut [21]). BBR testing of HMA thin beams eliminates the need for the chemically extraction of the asphalt binder from the pavement cores. Using the BBR approach, asphalt binder properties, such as creep compliance, can be backcalculated from the HMA results (ZoFKA [22]). Furthermore, multiple regression analysis successfully used the BBR creep measurements to predict the IDT creep values for different temperature levels at fixed time points (ZoFKA et al. [23][24]).

This paper presents the underlying concept of ANNs, briefly describes the creep testing procedures and experimental design, and discusses the process of training ANNs to correlate the IDT and BBR results for the HMA specimens. The paper also analyzes the feasibility of using ANNs for predicting the HMA creep compliance from the binder creep compliance and vice versa using the BBR experimental setup. Finally, the universality of trained ANNs was verified using an independent dataset.

\section{UNDERLYING CONCEPT OF ARTIFICIAL NEURAL NETWORKS}

Similar to a biological nervous system, an ANN consists of highly interconnected signal processors (neurons). Signals may only be allowed to travel through the neuron layers from input to output (feed-forward movement) or they can travel in both directions (feedback-, or loop- movement). Accordingly, two types of ANNs are available for solving complex problems (Haykin [1]). Fig. 1 illustrates the layout of a feed-forward ANN with one hidden layer, as modeled in MATLABßNeural Network Toolbox ${ }^{\mathrm{TM}_{5}}$ (Demuth et al. [25]). Each neuron in the input layer represents one input value $p$. The 
$p$ value is multiplied by a previously assigned weight $W$ to produce an input signal for each neuron in the hidden layer. The input signals are simultaneously sent to all of the neurons in the hidden layer through weighted connections. Each neuron in the hidden layer sums all of the weighted inputs and adds bias $b$ to produce an activation signal $n_{i j}$, as in the following equation:

$$
n_{i j}=\sum_{i}\left(W_{j} p_{i}\right)+b_{j}
$$

where:

$\mathrm{i}=$ number of inputs (summation index)

$\mathrm{j}=$ number of neurons in the hidden layer

\section{Hidden Layer}

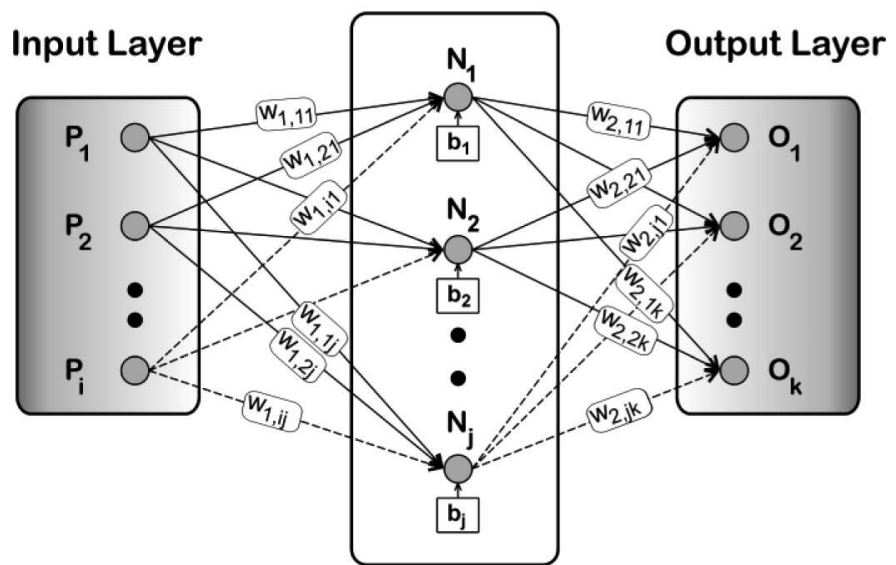

Fig. 1. Typical feed-forward ANN structure.

Next, the activation signal $n_{i j}$ is transformed into hidden output $a_{i j}$ using transfer function $f$. Four transfer functions are available for the modeling of the output: (1) threshold (hardlim), (2) linear (purelin), (3) logistic sigmoid (logsig), and (4) hyperbolic tangent sigmoid (tansig) (Haykin [1]). Eq. (2.2) through Eq. (2.5) show the mathematical expressions of the transfer functions:

$$
a_{i j}=\operatorname{hard} \lim \left(n_{i j}<0\right)=0 ; a_{i j}=\text { hard } \lim \left(n_{i j}>0\right)=1
$$

$$
a_{i j}=\operatorname{purelin}\left(n_{i j}\right)=n_{i j}
$$

$$
a_{i j}=\log \operatorname{sig}\left(n_{i j}\right)=\frac{1}{1+e^{-n_{i j}}}
$$




$$
a_{i j}=\operatorname{tansig}\left(n_{i j}\right)=\frac{1-e^{-n_{i j}}}{1+e^{-n_{i j}}}
$$

The hidden output $a_{i j}$ becomes an activation signal for a neuron in output layer as shown in the following equation:

$$
N_{j k}=\sum_{j}\left(W_{k} a_{i j}\right)+b_{k}
$$

where $k=$ number of outputs

The network output is then produced by the transformation of $N_{j k}$ into a predicted value $O_{k}=\mathrm{f}\left(N_{j k}\right)$ using one of the above functions - Eq. (2.2) through Eq. (2.5). Finally, the difference between predicted value $O_{k}$ and target value $T_{k}$ is evaluated by the following error function (Moody [26]):

$$
E_{k}=\frac{1}{2} \sum_{k}\left(T_{k}-O_{k}\right)^{2}
$$

The ultimate objective of training the ANN is to minimize error function $E_{k}$, thus improving the ANN's performance. This is done by adjusting the weight and bias value of each connection. While different minimization algorithms are available, the most popular is the back-propagation (BP) algorithm, as reported in the previously mentioned studies. The BP algorithm is a method for computing the gradient of the error function for each of training iterations with respect to the weights assigned to the feed-forward network. The ANN training process can be stopped when the gradient approaches a value of zero. A detailed description of the BP algorithm can be found elsewhere (Moody [26], Reed and Marks [27], Demuth et al. [25]).

\section{Creep testing Procedures}

An IDT test, the standard creep testing procedure for the HMA, induces the stress state similar to the stress state under a wheel load in the asphalt layer of pavement (RoQuE and Buttlar [18]). During the IDT test, a cylindrical specimen is loaded vertically along its length and displacements are measured on both faces of the specimen. From the test results, displacement curves are obtained under a constant load and the creep compliance function $D(t)$ is calculated using appropriate data interpretation procedures (Ropue and Buttlar [18], Zhang et al. [28], Christensen [29]). The IDT creep test for the HMA specimens is typically performed at three temperatures, $0^{\circ} \mathrm{C},-10^{\circ} \mathrm{C}$, and $-20^{\circ} \mathrm{C}$, regardless of the PG grade of the asphalt binder used in the mix (AASHTO [30]).

The BBR device is used to determine the creep compliance of asphalt binders as part of the AASHTO specification in the US (BAHIA et al. [19], AASHTO [31]). The BBR device is based on the 3-point bending setup commonly used to characterize 
construction materials. A constant force is applied to the middle of the beam specimen and beam deflections are measured throughout the test. The creep compliance function $D(t)$ can then be obtained from elementary Bernoulli-Euler beam theory (GERE and Timoshenko [32]).

Recently, a new approach was proposed to employ the BBR device to determine creep compliance of the HMA (ZoFKA et al. [20]). Testing thin HMA beams in the BBR device has several advantages over IDT testing: the BBR testing procedure is very easy and repeatable, sample size allows for a nearly nondestructive evaluation of the HMA in existing pavements, and the thin beams allow for an analysis of the effect of aging at relatively small pavement depths. Furthermore, by using appropriate composite materials models or other statistical techniques, the properties of asphalt binder can be backcalculated from the asphalt mixture results. This would eliminate the chemical extraction procedure that is typically used to obtain binder samples from the HMA (ZoFkA et al. [20]).

\section{EXPERIMENTAL PROTOCOL}

4.1. Materials

Ten different asphalt binders and two aggregate sources were used to produce twenty different HMA mixes considered in this study. The asphalt binders represented typical materials used in the colder climates in the US, including both modified and unmodified binders. The two aggregate types were limestone and granite. The nominal maximum aggregate size (NMAS) of the aggregate blends was $12.5 \mathrm{~mm}$. The optimum content of asphalt binder (6.0 and 6.9 percent for granite and limestone aggregates, respectively) in the mix design was determined at 4 percent air voids. The actual air content as measured on the gyratory specimens, ranged between 3.7 and 4.8 percent. Table 1 shows the types of the asphalt binders and the HMA mix identification system used throughout this study.

\subsection{Experimental Testing}

All 10 asphalt binders were aged using the Rolling Thin Film Oven Test (RTFOT) procedure (AASHTO [33]) and then tested in the BBR device with two replicates per each test temperature. Twenty HMA mixes were tested in the IDT and the BBR devices. Both creep tests were performed for $1000 \mathrm{~s}$ at three temperatures selected relative to the lower PG grade of the asphalt binder used in a given HMA specimen. Due to different temperature susceptibilities, the size of the temperature increments differed between materials, with a step of $12^{\circ} \mathrm{C}$ for the HMA and a smaller step of $6^{\circ} \mathrm{C}$ for asphalt binders (see Table 2). At least 3 replicates were used in the IDT testing per each temperature/material combination. 
Designation system for HMA.

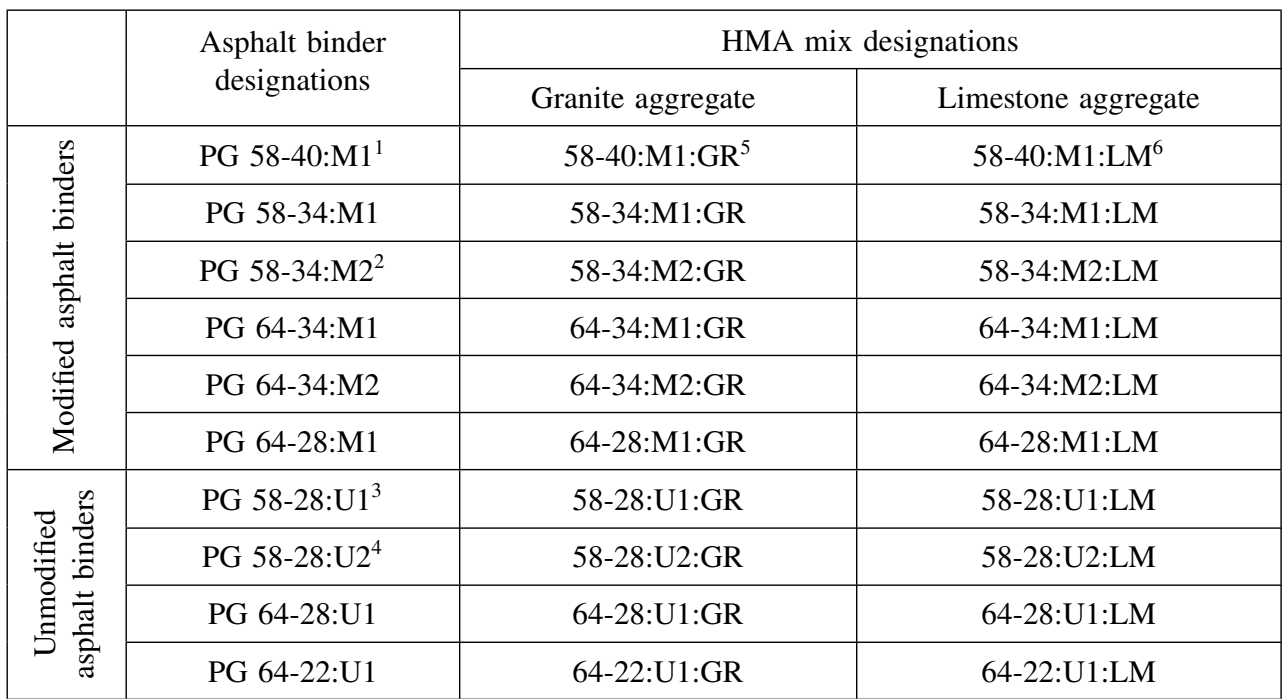

${ }^{1)} \mathrm{M} 1=$ Binder Modifier \#1; ${ }^{2} \mathrm{M} 2=$ Binder Modifier \#2; ${ }^{3)} \mathrm{U} 1=$ Unmodified binder (Source \#1); ${ }^{4)} \mathrm{U} 2=$ Unmodified binder (Source \#2); ${ }^{5} \mathrm{GR}=$ Granite Aggregate; ${ }^{6} \mathrm{LM}=$ Limestone Aggregate

The BBR testing of HMA beams followed a procedure similar to the asphalt binder BBR testing. The total number of HMA beams tested was approximately 600 . Twenty mixtures were tested at three temperature levels with an average of 10 replicates per each mixture/temperature combination. More details on the experimental design can be found elsewhere (Zofka and Yut [21], Zofka [22], Zofka et al. [23][24]).

Table 2

Test temperatures for HMA and asphalt binders.

\begin{tabular}{|l|l|l|}
\hline \multirow{2}{*}{ Test temperature value } & \multicolumn{2}{|c|}{ Test temperature level } \\
\cline { 2 - 3 } & HMA (IDT and BBR) & Asphalt binders (BBR) \\
\hline$\left(\mathrm{PG}^{1}+10\right)+12$ & H (High) & - \\
\hline$(\mathrm{PG}+10)$ & $\mathrm{I}$ (Intermediate) & $\mathrm{H}$ (High) \\
\hline$(\mathrm{PG}+10)-6$ & - & $\mathrm{I}$ (Intermediate) \\
\hline$(\mathrm{PG}+10)-12$ & $\mathrm{~L}($ Low $)$ & $\mathrm{L}$ (Low) \\
\hline
\end{tabular}

${ }^{1} \mathrm{PG}$ refers to the lower PG limit (i.e. the second number in the PG designation in Table 1) 


\section{TRAINING ARTIFICIAL NEURAL NETWORKS ON EXPERIMENTAL DATA}

In this study, three different ANNs were considered and trained separately for the following cases:

- Case A: ANN model to predict the IDT HMA creep compliance from the BBR tests on thin HMA beams.

- Case B: ANN model to predict the HMA creep compliance from the BBR tests on asphalt binder.

- Case C: ANN model to backcalculate the creep compliance of the asphalt binders from the BBR tests on thin HMA beams.

The datasets, training processes, and verification results of the above cases are discussed next.

\subsection{Compiling the Dataset and Training the ANNs}

The datasets used for ANN training was compiled from the BBR and IDT test results. The following variables were considered: creep compliance, $D(t)$, performance grade PG (high and low temperature grades), presence of binder modifier, testing temperature, aggregate type, and air void content. Real (numerical) values were used for the inputs of $D(t)$, performance grade, and air voids, while the remaining variables were assigned binary (0/1) inputs. Three separate datasets were created for cases A, B, and C, for which separate ANNs were trained to simultaneously predict $D(t)$ at 16, 60, 120, 240, 500, and $1000 \mathrm{~s}$. Table 3 summarizes the datasets used for the ANN training.

The typical architectural parameters of the ANN are the number of inputs $(i)$, the number of outputs $(k)$, the number of hidden layers, and number of neurons in each hidden layer $(j)$. The ANN parameters and transfer functions used in this study are summarized in Table 4 with the dataset descriptions for each case. Note that all three cases utilized six measured values of $D(t)$ (at 16,60,120,240,500, and $1000 \mathrm{~s}$ ) as input variables but include different combinations of explanatory variables (factors). Those combinations were finalized through iterative processes in which only the variables that significantly contributed to the minimization of the mean-squared error (MSE) in a particular case were included in the corresponding dataset.

Additionally, the effect of the amount of neurons in the hidden layers on the goodness of fit was evaluated by training ANN with 5 to 30 neurons for each case (A, B, and C). Fig. 2 illustrates the change in R-squared and the coefficient of variation (COV) with an increase in the number of neurons. The R-squared trends fluctuate around 0.99, 0.98 , and 0.999 for cases A, B, and C, respectively. Although the difference between cases in terms of R-squared is statistically significant, it is sufficiently small to be practically neglected. On the other hand, the three cases (A, B, and C) yield more distinctive trends in the variability of results, as measured by COV. Fig. 2 shows Case $\mathrm{C}$ with the lowest $\mathrm{COV}$ at about 5 to 7 percent, Case B with a COV of 15 to 17 percent, and Case A with the highest COV of around 20 percent. Possible reasons for 
Summary of variables for the ANN training.

\begin{tabular}{|c|c|c|c|c|c|c|c|}
\hline Variable & Index & $\begin{array}{c}\text { Designation } \\
\text { (Input/ Target) }\end{array}$ & $\begin{array}{c}\text { Value } \\
\text { Assigned } \\
\text { (Real/ } \\
\text { Binary) }\end{array}$ & $\begin{array}{l}\text { Range } \\
\text { (min; } \\
\max )\end{array}$ & $\begin{array}{c}\text { Level } \\
1\end{array}$ & $\begin{array}{l}\text { Level } \\
2\end{array}$ & $\begin{array}{l}\text { Level } \\
3\end{array}$ \\
\hline $\begin{array}{l}\text { High temperature } \\
\text { grade (Tmax), }{ }^{\circ} \mathrm{C}\end{array}$ & PG1 & Input & Real & $58 ; 64$ & & & \\
\hline $\begin{array}{l}\text { Low temperature } \\
\text { grade (Tmin), }{ }^{\circ} \mathrm{C}\end{array}$ & PG2 & Input & Real & $-40 ;-22$ & & & \\
\hline $\begin{array}{l}\text { Modifier, } \\
\text { Yes/No [1/0] }\end{array}$ & Mod & Input & Binary & N/A & 1 & 0 & \\
\hline $\begin{array}{l}\text { Air Voids } \\
\text { Content, \% }\end{array}$ & AV & Input & Real & $3.72 ; 4.80$ & & & \\
\hline $\begin{array}{l}\text { Tmin+12 } \\
\text { for mix, } \\
\text { Tmin for } \\
\text { binders, }{ }^{\circ} \mathrm{C}\end{array}$ & $\mathrm{TH}$ & Input & Binary & N/A & 1 & 0 & 0 \\
\hline $\begin{array}{l}\text { Tmin for mix, } \\
\text { Tmin- } 6 \text { for } \\
\text { binders, }{ }^{\circ} \mathrm{C}\end{array}$ & TI & Input & Binary & N/A & 0 & 1 & 0 \\
\hline $\begin{array}{l}\text { Tmin-12 for mix, } \\
\text { Tmin-12 for } \\
\text { binders, }{ }^{\circ} \mathrm{C}\end{array}$ & $\mathrm{TL}$ & Input & Binary & N/A & 0 & 0 & 1 \\
\hline $\begin{array}{l}\text { Binder creep } \\
\text { compliance from } \\
\text { BBR test, } D(t) \\
(1 / \mathrm{GPa})\end{array}$ & BBR_Bind & $\begin{array}{l}\text { Input (Case B)/ } \\
\text { Target (Case C) }\end{array}$ & Real & $0.8 ; 59$ & & & \\
\hline $\begin{array}{l}\text { Aggregate Type } \\
\text { - Granite }\end{array}$ & AGG1 & Input & Binary & N/A & 0 & 1 & \\
\hline $\begin{array}{l}\text { Aggregate Type } \\
\text { - Limestone }\end{array}$ & AGG2 & Input & Binary & N/A & 1 & 0 & \\
\hline $\begin{array}{l}\text { Mix creep } \\
\text { compliance from } \\
\text { BBR test, } D(t) \\
(1 / \mathrm{GPa})\end{array}$ & BBR_Mix & $\begin{array}{c}\text { Target (Case B)/ } \\
\text { Input (Cases A } \\
\text { and C) }\end{array}$ & Real & $0.05 ; 1.48$ & & & \\
\hline $\begin{array}{l}\text { Mix creep } \\
\text { compliance from } \\
\text { IDT test, } D(t) \\
(1 / \mathrm{GPa})\end{array}$ & IDT_Mix & Target (Case A) & Real & $0.03 ; 2.32$ & & & \\
\hline
\end{tabular}

such differences are discussed in the following section. Based on this assessment of the effect of the number of neurons on ANN goodness of fit, an amount of 20 neurons was selected to be used in all cases so that the results are comparable. This number of neurons also satisfies the "golden rule" of ANNs, to have approximately half as many neuron connections (see Table 4) as data points in the dataset (SARLE [34]).

To create and evaluate each case's ANN, each dataset was randomly divided into three subsets - training, validation, and testing - containing 60 percent, 20 percent, and 20 percent of data points, respectively. First, the ANN performed as many iterations 
Table 4

Summary of ANN parameters.

\begin{tabular}{|c|c|c|c|}
\hline Case & A & B & $\mathrm{C}$ \\
\hline Objective & $\begin{array}{l}\text { Predict IDT_Mix } \\
\text { from BBR_Mix }\end{array}$ & $\begin{array}{l}\text { Predict BBR_Mix } \\
\text { from BBR_Bind }\end{array}$ & $\begin{array}{l}\text { Predict BBR_Bind } \\
\text { from BBR_Mix }\end{array}$ \\
\hline Target & $\begin{array}{l}\text { IDT_Mix at } 16,60,120 \text {, } \\
240,500,1000) \mathrm{s}\end{array}$ & $\begin{array}{l}\text { BBR_Mix at } 16,60,120, \\
240,500,1000 \mathrm{~s}\end{array}$ & $\begin{array}{l}\text { BBR_Bind at } 16(60,120, \\
240,500,1000 \mathrm{~s}\end{array}$ \\
\hline Inputs & $\begin{array}{l}\text { BBR_Mix at } 16,60, \\
120,240,500,1000 \mathrm{~s} \\
\text { PG1,PG2,TH,TI,TL }\end{array}$ & $\begin{array}{l}\text { BBR_Bind at 16, 60, } \\
\text { 120, 240, 500, 1000 s } \\
\text { PG1, PG2, Mod, TH, TI, } \\
\text { TL, AV, AGG1, AGG2, }\end{array}$ & $\begin{array}{l}\text { BBR_Mix at 16, 60, } \\
120,240,500,1000 \mathrm{~s} \\
\text { PG1, PG2, Mod, TH, } \\
\text { TI, TL }\end{array}$ \\
\hline \# of inputs & 11 & 15 & 12 \\
\hline \# of outputs & 6 & 6 & 6 \\
\hline $\begin{array}{l}\text { \# of hidden } \\
\text { layers }\end{array}$ & 1 & 1 & 1 \\
\hline $\begin{array}{l}\text { \# of neurons } \\
\text { in hidden layer }\end{array}$ & 20 & 20 & 20 \\
\hline $\begin{array}{l}\text { Total \# of } \\
\text { connections }\end{array}$ & 340 & 420 & 360 \\
\hline $\begin{array}{l}\text { \#of data } \\
\text { points }\end{array}$ & 660 & 594 & 594 \\
\hline $\begin{array}{l}\text { Transfer } \\
\text { functions }\end{array}$ & $\begin{array}{l}\text { tan sig (hidden layer) } \\
\text { purelin (output layer) }\end{array}$ & $\begin{array}{l}\text { tan sig (hidden layer) } \\
\text { purelin (output layer) }\end{array}$ & $\begin{array}{l}\text { tan sig (hidden layer) } \\
\text { purelin (output layer) }\end{array}$ \\
\hline
\end{tabular}

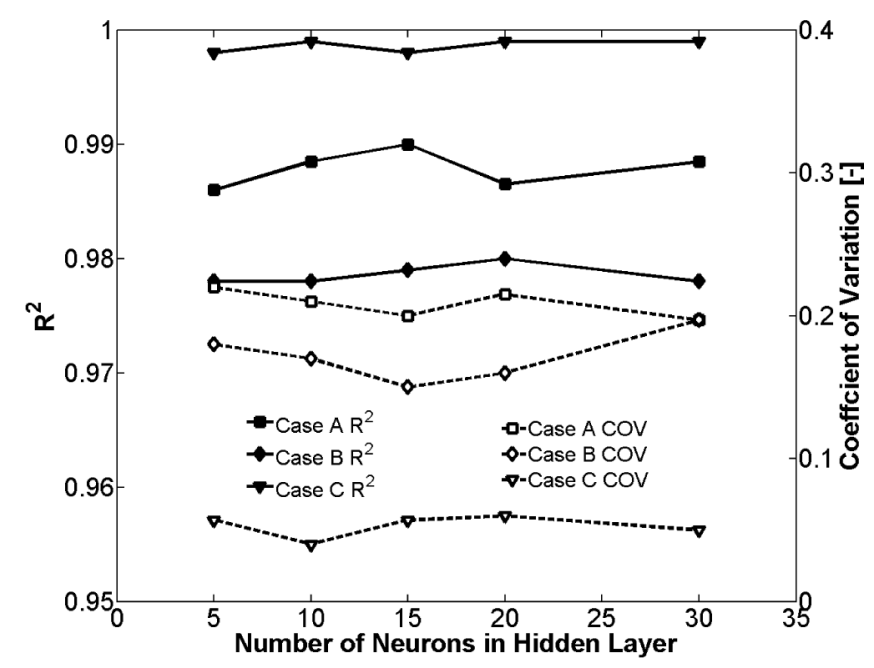

Fig. 2. Effect of ANN structure on goodness of fit.

as required to minimize the MSE on the training subset. The validation subset was then used to ensure that there was no over-fitting in the final results. Lastly, the testing subset provided an independent measure of how well the network could be expected 
to perform on data not used in the training process. The prediction for each subset was evaluated by the level of correlation $\left(R^{2}\right)$ between predicted (Output) and measured (Target) values of $D(t)$.

It should be noted that originally three different training/validation/testing subset divisions were used in this study $(50 / 25 / 25,60 / 20 / 20$, and 70/15/15). It was found however that they did not yield any significant difference in terms of goodness of fit and therefore only the results of the 60/20/20 division are reported in this paper.

\subsection{Analysis of the ANN Results}

Fig. 3, Fig. 4, and Fig. 5 include charts of the correlation between the output and target values of $D(t)$ for all values in cases $\mathrm{A}, \mathrm{B}$, and $\mathrm{C}$, respectively. Analysis of the $R^{2}$ values for Case A shown in Fig. 3 suggests that the HMA creep compliance values from the IDT and the BBR beams test are highly correlated $\left(R^{2}=0.99\right)$. Similarly, Fig. 4 and Fig. 5 show high goodness of fit values for cases $\mathrm{B}$ and $\mathrm{C}$ respectively, which illustrate the ability of the ANNs to predict the creep compliance of the HMA mix from the creep compliance of asphalt binders and vice versa. It can also be observed that the overall $R^{2}$ value for each dataset does not differ much between the cases with values ranging between 0.98 and 0.999 .

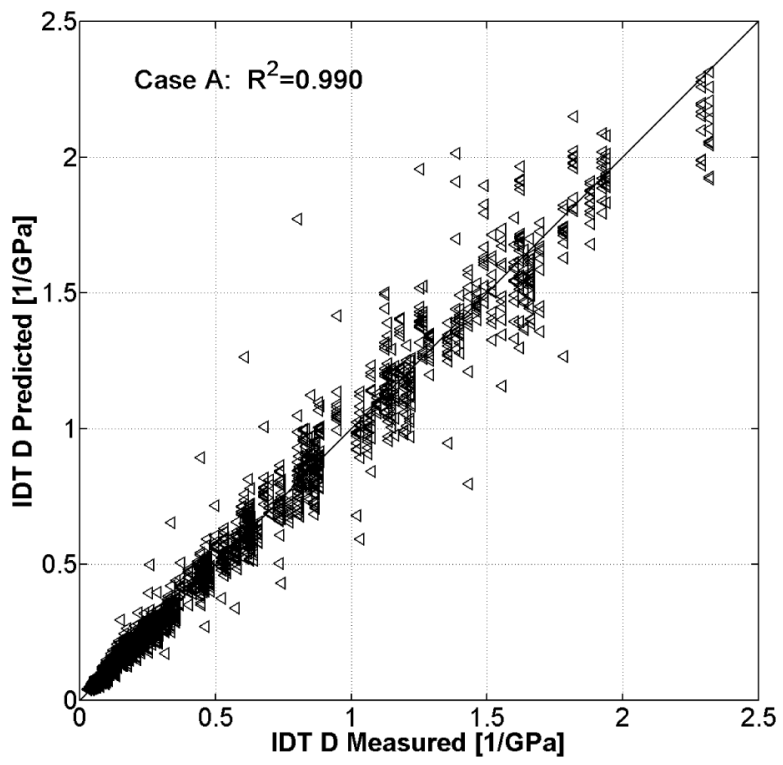

Fig. 3. Correlation charts of ANN outputs versus targets for Case A (all values).

It should be noted that the similarly high correlations between ANN predictions and the measured values in Cases A, B, and $\mathrm{C}$ were accompanied by different levels 


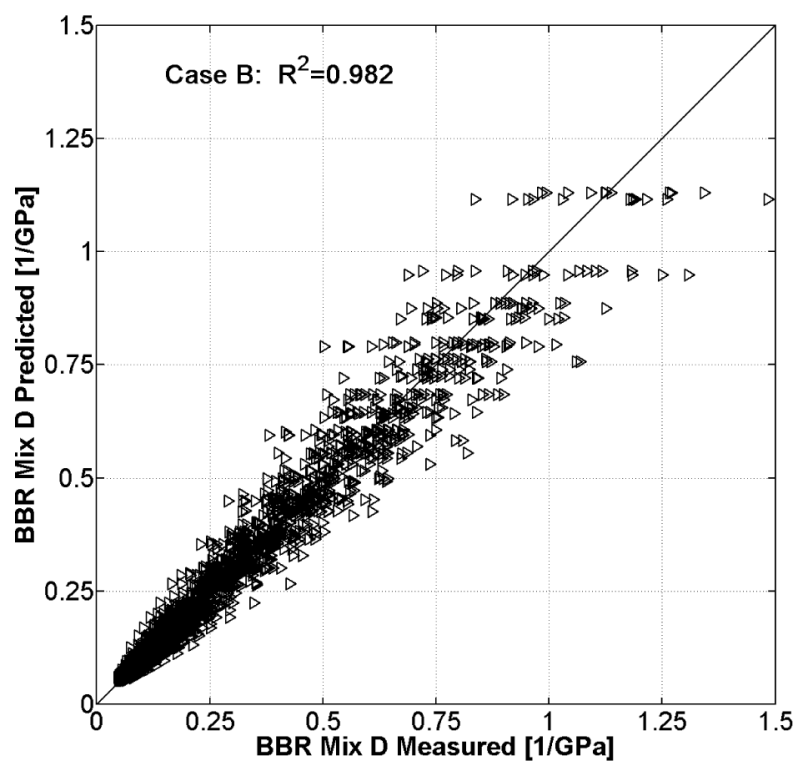

Fig. 4. Correlation charts of ANN outputs versus targets for Case B (all values).

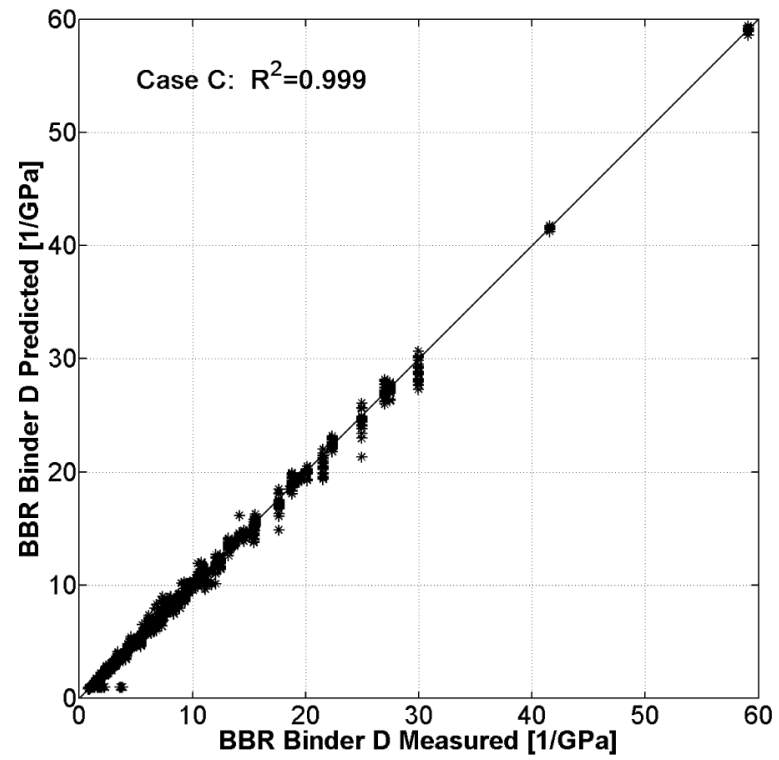

Fig. 5. Correlation charts of ANN outputs versus targets for Case C (all values). 
of variability in the predicted values. Case A (predict IDT $D(t)$ Mix from $B B R D(t)$ Mix) had the greatest dispersion of ANN-predicted values as seen in the correlation chart found in Fig. 3. Case B (predict BBR $D(t)$ Mix from BBR $D(t)$ Binder) exhibited noticeably lower variability (Fig. 4). Finally, Case C (predict $B B R D(t)$ Binder from $B B R D(t)$ Mix) yielded a very low variation in predicted values (Fig.5). One possible explanation for such a phenomenon is that in Case A, the variation in the ANN predictions was affected by variations in both the BBR and the IDT tests performed on the HMA samples which typically produces higher variability than asphalt binder testing.

To further investigate the ANN predictions, the predicted and experimentally determined creep compliance curves were constructed and compared separately for each case. In practical applications, such as the previously mentioned M-EPDG approach, the entire creep compliance functions are used to predict pavement performance as opposed to discrete values.

\subsection{Analysis of Creep Curves from ANN Simulation}

Based on the ANN-predicted and test measured values at 16,60, 120, 240, 500, and $1000 \mathrm{~s}$, creep compliance functions were constructed for each considered case (A, B, and C). Altogether, 60 pairs of creep functions were plotted for Case A and 54 pairs of creep curves were plotted for both Case B and C. The curves were then evaluated in terms of the percent error between the output (predicted) and target (measured) values. It was found that at 95 percent reliability the average percent error of the predicted creep compliance values were approximately 40, 30, and 10 percent for Cases A, B, and $\mathrm{C}$, respectively. Examples of the creep compliance curves and their associated prediction errors are found in Fig. 6, Fig. 7, and Fig. 8. The ANN-predicted errors shown in these figures correspond well with the variation in the BBR-measured values of the HMA creep compliance reported elsewhere (Zofka 2007; Zofka et al. 2008b).

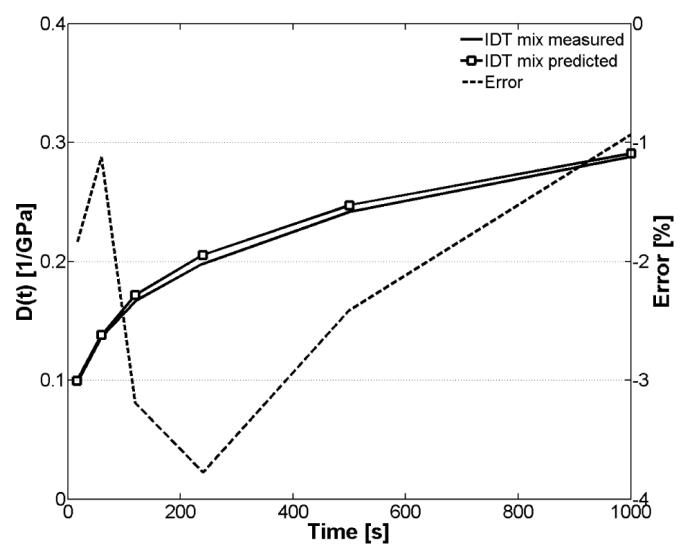

Fig. 6. Representative Creep Curves for Case A. 


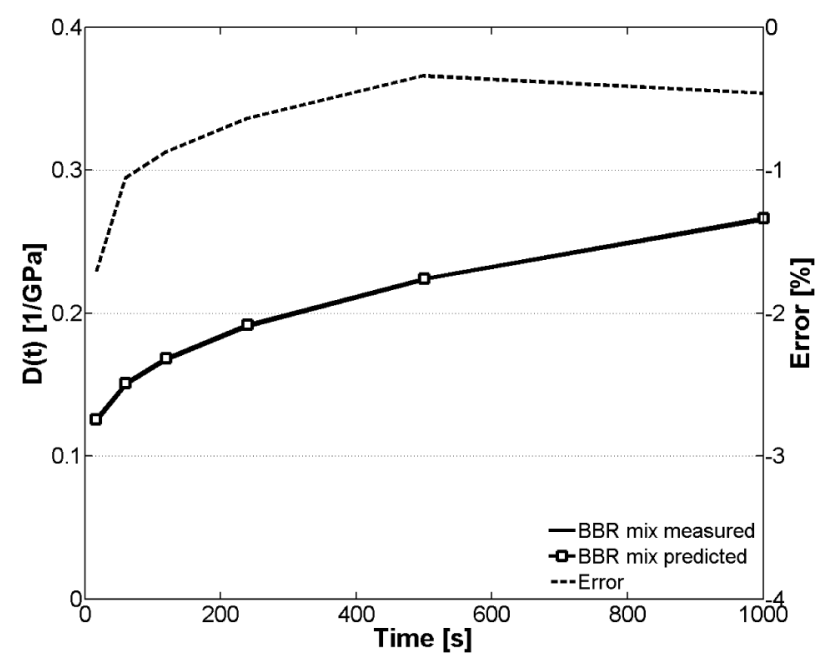

Fig. 7. Representative Creep Curves for Case B.

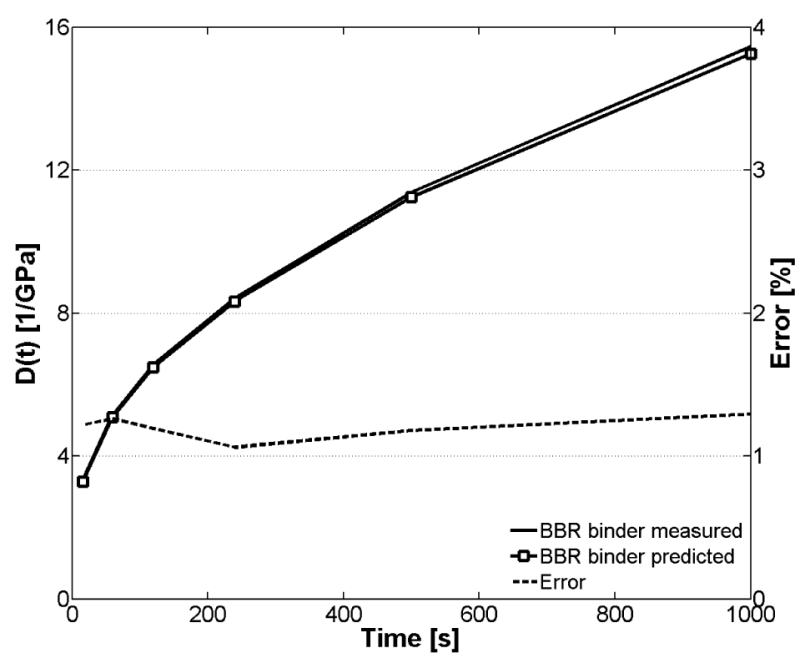

Fig. 8. Representative Creep Curves for Case C.

\subsection{Verifying the Universality of the ANN on InDEPENDENT Data}

As shown above, the ANNs trained in this study using the BBR and IDT data produced a high correlation between measured and predicted creep compliance values. The final phase of this study was intended to verify the universality of trained ANNs, e.g. their ability to retain a high correlation between measured and predicted values 
when using entirely independent data. The verification dataset included the BBR-and IDT-measured values of $D(t)$ at $16,60,120$, and 240 s for the following two HMAs:

Warm Mixed Asphalt (WMA) with PG 58-34 modified asphalt binder and granite aggregate including up to $20 \%$ of Reclaimed Asphalt Pavement (RAP), $4 \%$ air voids (WMA:58-34:M:RAP).

Dense-graded HMA with PG 58-28 unmodified binder and granite aggregate including 5\% of manufactured waste shingles, $4 \%$ air voids (58-28:U:GRS).

Corresponding asphalt binders were aged using the Pressure Aging Vessel (PAV) procedure (AASHTO [35]) which is different from the RTFOT procedure used for the development of the ANNs. To eliminate this inconsistency, simple adjustment factors were applied to the PAV values. The factors were determined as a function of the test temperature using a large creep compliance binder database (Marasteanu et al. [36]).

The previously trained ANNs were simulated using verification data as inputs, and the produced outputs were then compared with target (measured) values. It was noted that the range of prediction errors for the verification dataset was significantly wider than that for the training dataset. The percent error in the predicted creep compliance values ranged between approximately 10 to 60 percent for Case A, 5 to 55 percent for Case B, and 20 to 80 percent for Case C. The comparison of creep curves for Case A (Fig. 9a) yielded a fairly high level of prediction (within 10-20 percent from the measured values) for the RAP-modified mix WMA:58-34:M:RAP. However, the ANN simulation of the same case for the HMA mix with 5\% shingles (58-28:U:GRS) produced remarkably high deviation (within 40 to 60 percent) from the measured values (Fig. 9a). Fig. 10 illustrates the opposite trend for Case B (15 to 60 percent error for WMA:58-34:M:RAP and only 5 to 15 error for 58-28:U:GRS). In Case C, ANN failed to yield any reasonable level of prediction for both type of binders, yielding 20 to 80 percent deviation from measured $D(t)$ values.

Higher error in the predictions generated by the verification datasets can be primarily attributed to the differences in the material composition: the verification set contained recycled additives that typically introduce higher variability into any characterization testing, and such materials were not used when developing the ANNs structures. Furthermore, the binder aging conversion factors (from PAV to RTFOT) as well as binder type may contribute up to $10 \%$ to the prediction error. Aggregate mechanical properties and gradation distribution also differed in the verification data which increased further the error of prediction. One potential solution to improve prediction accuracy is to expand and to diversify training dataset, and to implement additional factors that would account for material heterogeneity. 

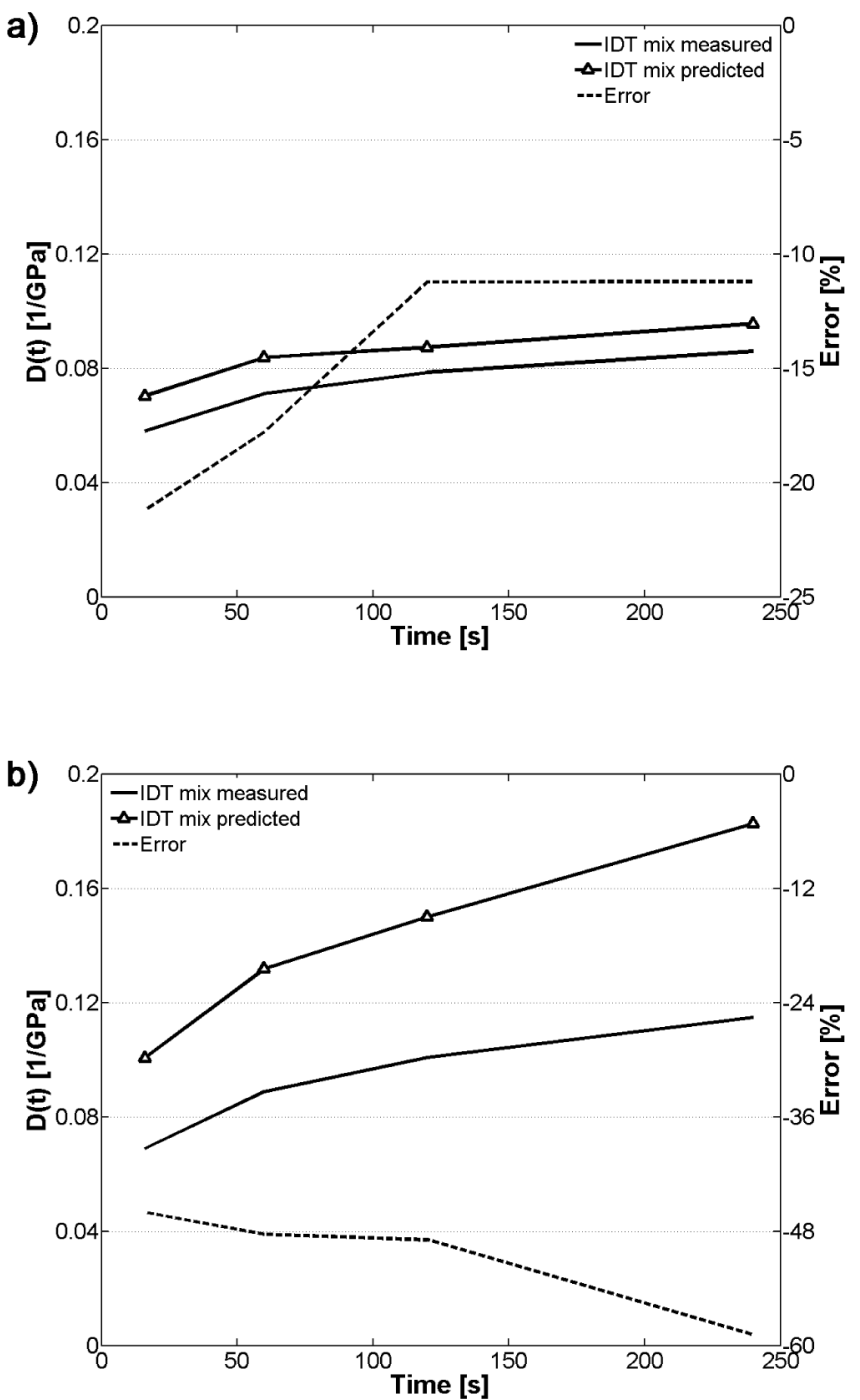

Fig. 9. Case A Verification: Creep Curves for a) binder WMA:58-34:M:RAP, b) binder 58-28:U:GRS 

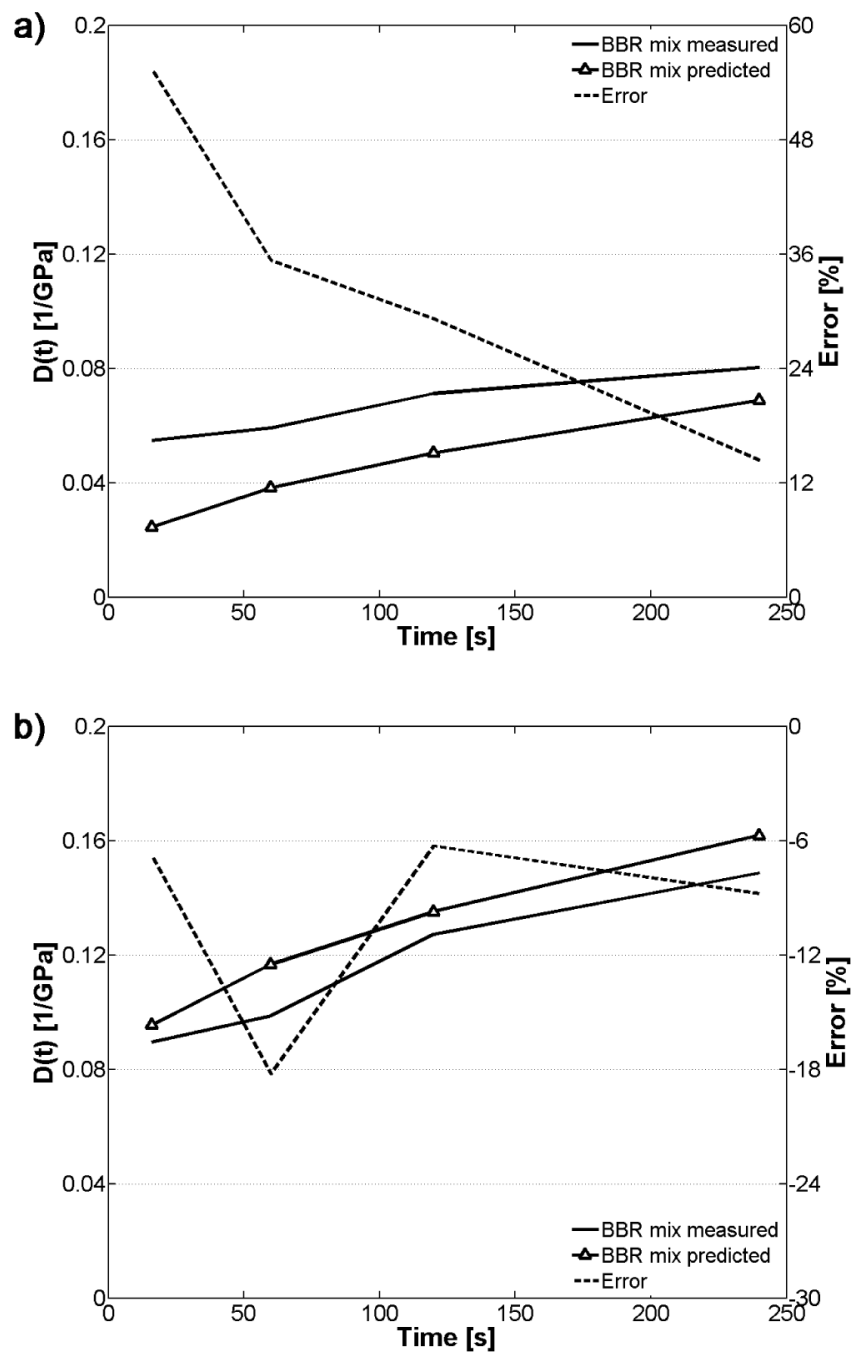

Fig. 10. Case B Verification: Creep Curves for a) binder WMA:58-34:M:RAP, b) binder 58-28:U:GRS. 
a)

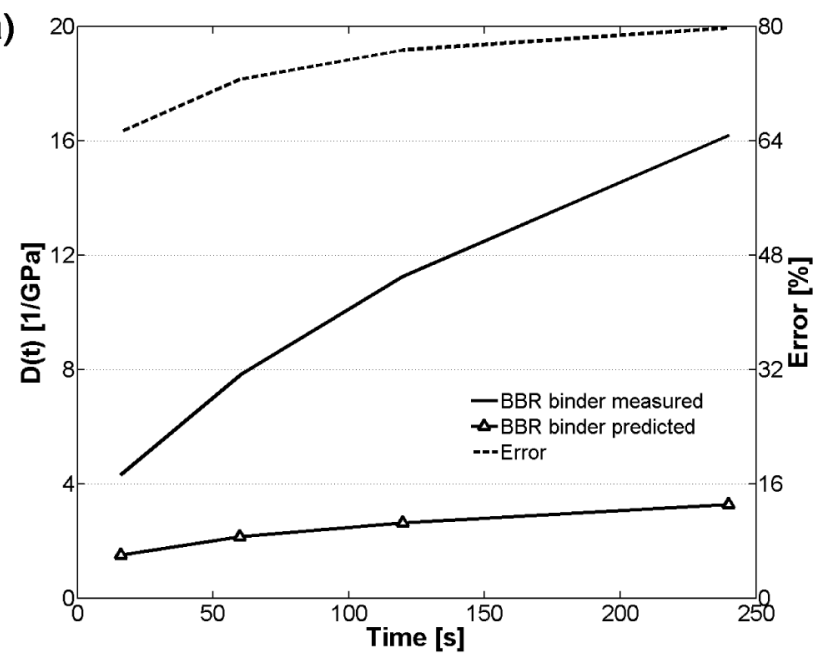

b)

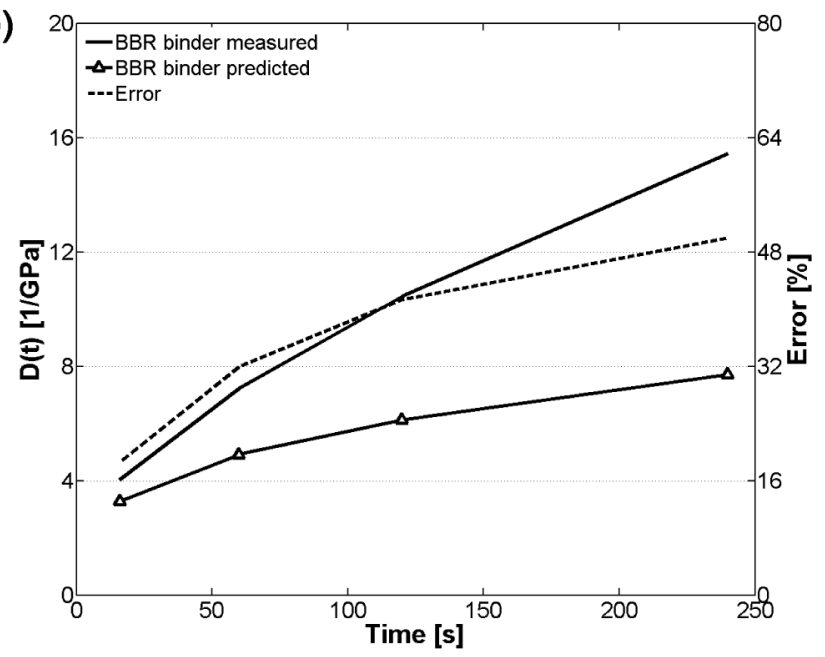

Fig. 11. Case C Verification: Creep Curves for a) binder WMA:58-34:M:RAP, b) binder 58-28:U:GRS. 


\section{Conclusions}

This paper explores the feasibility of using ANNs to predict the creep compliance of asphalt binders from the BBR tests on the HMA specimens and vice versa. It also evaluates the ANNs ability to correlate BBR data for HMA beams with the results of the more traditional IDT testing on short HMA cylinders.

The experimental effort described in this paper included the IDT and BBR results for 20 HMA mixes with different rheological properties at three temperature levels. The 20 HMA mixes were produced by combining 10 modified and unmodified binders of different performance grades with two types of aggregates - granite and limestone. For the full dataset, the RTFOT-aged binders were also tested in the BBR device in accordance with the standard AASHTO procedure.

The experimentally obtained creep compliance values for the HMA and binders were used to train feed-forward, back-propagation Artificial Neural Networks. Separate ANNs were considered for the following three cases:

1. Case A: predict the IDT HMA creep compliance from the BBR tests on thin HMA beams.

2. Case B: predict the creep compliance of the HMA mix from the BBR tests results on the corresponding asphalt binder.

3. Case C: backcalculate creep compliance of the binder from the BBR test results on the corresponding HMA beams.

It was found that the ANN prediction models demonstrated very high correlation of 97 to 99 percent between ANN-predicted and experimentally measured values for all three cases albeit with different levels of variability. Furthermore, the creep compliance curves for all three cases showed fairly good agreement (5 to 20 percent error) with measured values. Lastly, the universality of the trained ANNs was tested by using the BBR and IDT test results from the independent source. The simulation results showed significantly higher level of deviation from target values (10 to 80 percent error). High error values could be attributed to the significantly different material composition of the verification set. The materials in the verification dataset included Reclaimed Asphalt Pavement (RAP) and manufactured waste shingles. In addition, the gradation and mechanical properties of the aggregate differed from the original material used to develop the ANNs.

Based on an analysis of the ANN training and verification results produced in this study, it can be reasonably concluded that ANNs are suitable for predicting the creep compliance of the HMA from the BBR-measured creep compliance of the binder, especially in the initial material evaluation process. Furthermore, trained ANNs can match the BBR-measured creep compliance of HMAs with the creep compliance obtained from the more traditional IDT procedure. Predicted HMA creep compliance values can then be used in the pavement performance models included in the M-EPDG. However, one should keep in mind that ANNs may produce high prediction errors if material 
composition is significantly different from the original material used to calibrate the ANNs.

\section{ACKNOWLEDGEMENTS}

The materials used in this paper were obtained from the National Pooled Fund Study 776 (Marasteanu et al. [36]). All experimental testing was conducted at the University of Minnesota under the supervision of Professor Mihai Marasteanu to whom the authors are sincerely grateful. The authors also thank Mr. Tim Clyne for providing independent data from MnROAD Research facility.

\section{REFERENCES}

1. S. HaYкin, Neural networks and learning machines, Prentice Hall, New York, NY 1999.

2. I. Flood, N. Kartam, Neural networks in civil engineering. I: Principles and understanding. Journal of Computing in Civil Engineering, 8, 131-48, 1994a.

3. I. Flood, N. Kartam, Neural networks in civil engineering. II: Systems and application. Journal of Computing in Civil Engineering, 8, 149-62, 1994b.

4. M. Dougherty, A review of neural networks applied to transport. Transportation Research Part C: Emerging Technologies, 3, 247-60, 1995.

5. N.O. Аттон-Окine, S. Mensah, Potential applications of system identification techniques in pavement performance modeling. Proceedings of the Second International Symposium on Maintenance and Rehabilitation of Pavements and Technological Control, National Center for Asphalt Technology, Auburn, Alabama, 2001.

6. S. Сhou, T.K. Pellinen, Assessment of construction smoothness specification pay factor limits using artificial neural network modeling. Journal of Transportation Engineering, 131, 563-70, 2005.

7. R.A. TAREfDer, L. White, M. Zaman, Development and application of a rut prediction model for flexible pavement. Transportation Research Record 1936, 201-9, 2005a.

8. R.A. TARefder, L. White, M. Zaman, Neural network model for asphalt concrete permeability. Journal of Materials in Civil Engineering, 17, 19-27, $2005 \mathrm{~b}$.

9. H. Ceylan, A. Guclu, E. Tutumluer, M.R. Thompson, Backcalculation of full-depth asphalt pavement layer moduli considering nonlinear stress-dependent subgrade behavior. International Journal of Pavement Engineering, 6, 171-82, 2005.

10. A. Molenaar, A. Meerkerk, M. Miradi, T. van der Steen, Performance of porous asphalt concrete. Journal of the Association of Asphalt Paving Technologists, 75, 1053-94, 2006.

11. C. Huang, Y.M. Najuar, S.A. Romanoschi, Predicting asphalt concrete fatigue life using artificial neural network approach. Paper No. 07-1607, 86th Transportation Research Board Annual Meeting (CD-ROM), Transportation Research Board, National Research Council, Washington, DC. 2007.

12. M. ZEGHAL, Thermal cracking prediction using artificial neural network. In Al-Qadi, Scarpas \& Loizos (Ed.), Pavement Cracking, Taylor and Francis Group, 379-86, 2008a.

13. M. ZeGHaL, Modeling the creep compliance of asphalt concrete using the artificial neural network technique. Proceedings of the Annual Congress of the Geo-Institute of ASCE (GeoCongress 2008), New Orleans, LA, 1-7, 2008b. 
14. A.T. LaCroix, Y.R. Kim, S.R. Ranjithan, Backcalculation of dynamic modulus from resilient modulus of asphalt concrete with an artificial neural network. Transportation Research Record: Journal of Transportation Research Board, 2057, 107-13, 2008.

15. H. Ceylan, K. Gopalakrishnan, M.B. Bayrakc, Neural networks based concrete airfield pavement layer moduli backcalculation. Civil Engineering and Environmental Systems, 25, 185-99, 2008.

16. F. Xiao, S.N. Amirkhanian, Artificial neural network approach to estimating stiffness behavior of rubberized asphalt concrete containing reclaimed asphalt pavement. Journal of Transportation, 135, 8, 580-9, 2009.

17. J.P. Hallin, et al., Development of the 2002 guide for the design of new and rehabilitated pavement structures: Phase II. Report for National Cooperative Highway Research Program, Transportation Research Board, National Research Council, Washington, DC., 2004.

18. R. Roque, W.G. Buttlar, The development of a measurement and analysis system to accurately determine asphalt concrete properties using the Indirect Tensile mode. Journal of the Association of Asphalt Paving Technologists, 61, 304-28, 1992.

19. H. Bahia, D.A. Anderson, D. Christensen, The Bending Beam Rheometer; a simple device for measuring low-temperature rheology of asphalt binders. Journal of Association of Asphalt Paving Technologists, 61, 117-53, 1992.

20. A. Zofka, M. Marasteanu, X. Li, T. Clyne, J. McGraw, Simple method to obtain asphalt binders low temperature properties from asphalt mixtures properties. Journal of the Association of Asphalt Paving Technologists, 80, 255-82, 2005.

21. A. Zofka, I. Yut, Alternative procedure for determination of hot mix asphalt creep compliance. ASTM Journal of Testing and Evaluation, 39, 1, 1-11, 2011.

22. A. ZoFKa, Investigation of asphalt concrete creep behavior using 3-point bending test. Ph.D. dissertation, University of Minnesota, Minneapolis, MN, 2007.

23. A. Zofka, M. Marasteanu, M. Turos, Determination of asphalt mixture creep compliance at low temperatures using thin beam specimens. Transportation Research Record 2057, 134-9, 2008a.

24. A. Zofka, M. Marasteanu, M. Turos, Investigation of asphalt mixture creep compliance at low temperatures. Journal of Road Materials and Pavement Design, 9, 269-286, 2008b.

25. H. Demuth, M. Beale, M. Hagan, Neural network toolbox 5 user's guide. The MathWorks, Inc., Natick, MA, 2007.

26. J.E. Moody, The effective number of parameters: an analysis of generalization and regularization in nonlinear learning systems. Advances in neural information processing systems 4, Morgan Kaufman Publishers, San Mateo, CA, 1992.

27. R.D. REED, R.J. MARKs, Neural smithing: supervised learning in feedforward artificial neural networks, The MIT Press, Cambridge, MA, 1992.

28. W. Zhang, A. Drescher, D.E. Newcomb, Viscoelastic analysis of diametral compression of asphalt concrete. Journal of Engineering Mechanics, 123, 6, 596-603, 1997.

29. D. Christensen, Analysis of creep data from Indirect Tension test on asphalt concrete. Journal of the Association of Asphalt Paving Technologists, 67, 458-77, 1998.

30. AASHTO Standard T 322-03, Determining the creep compliance and strength of hot-mix asphalt (HMA) using the Indirect Tensile test device. Standard Specifications for Transportation Materials and Methods of Sampling and Testing, AASHTO, Washington, DC, 2005a.

31. AASHTO Standard T313-05, Standard method of test for determining the flexural creep stiffness of asphalt binder using the Bending Beam Rheometer (BBR), Standard Specifications for Transportation Materials and Methods of Sampling and Testing, AASHTO, Washington, DC, 2005b.

32. J.M. Gere, S.P. Timoshenko, Mechanics of materials, Third Edition, PWS-KENT Publishing Company, Boston, MA, 1990. 
33. AASHTO Standard T240-03, Standard method of test for effect of heat and air on a moving film of asphalt (Rolling Thin-Film Oven Test), Standard Specifications for Transportation Materials and Methods of Sampling and Testing, AASHTO, Washington, DC, 2005c.

34. W. SARLE, Neural Networks: Frequently Asked Questions. Retrieved December 1, 2011, from ftp://ftp.sas.com/pub/neural/FAQ.html, 1997.

35. AASHTO Standard PP, Practice for accelerated aging of asphalt binder using Pressurized Aging Vessel (PAV), Standard Specifications for Transportation Materials and Methods of Sampling and Testing, AASHTO, Washington, DC, 1998.

36. M. Marasteanu, et al., Investigation of low temperature cracking in asphalt pavements - National Pooled Fund Study 776. Report MN/RC 2007-43, Minnesota Department of Transportation, St. Paul, MN, 2007.

\section{Extended Abstract}

Creep compliance of the hot-mix asphalt (HMA) is a primary input of the pavement thermal cracking prediction model in the recently developed Mechanistic-Empirical Pavement Design Guide (M-EPDG) in the US. The HMA creep compliance is typically determined from the Indirect Tension (IDT) tests and requires complex experimental setup. On the other hand, creep compliance of asphalt binders is determined from a relatively simple three- point bending test performed in the Bending Beam Rheometer (BBR) device. This paper discusses a process of training an Artificial Neural Network (ANN) to correlate the creep compliance values obtained from the IDT with those from an innovative approach of testing HMA beams in the BBR. In addition, ANNs are also trained to predict HMA creep compliance from the creep compliance of asphalt binder and vice versa using the BBR setup. All trained ANNs exhibited a very high correlation of 97 to 99 percent between predicted and measured values. The binder creep compliance curves built on the ANN-predicted values also exhibited good correlation with those obtained from laboratory experiments. However, the simulation of trained ANNs on the independent dataset produced a significant deviation from the expected values which was most likely caused by the differences in material composition, such as aggregate type and gradation, presence of recycled additives, and binder type.

Remarks on the paper should be sent to the Editorial Office

not later than September 30, 2012
Received December 12, 2011 revised version June 10, 2012 